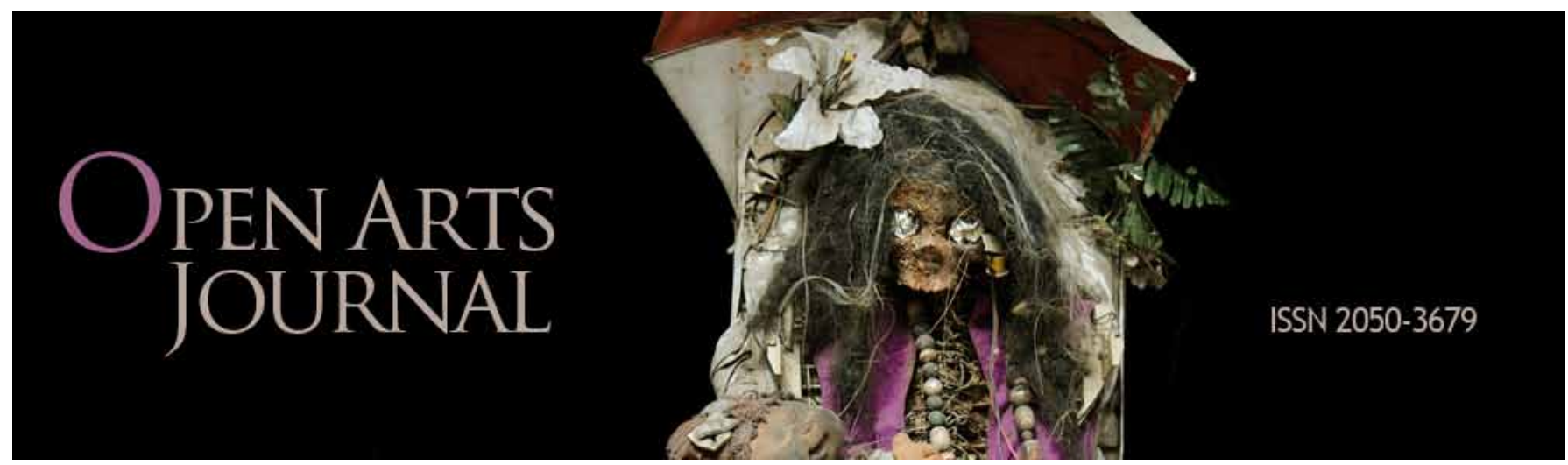

\title{
ELECTRONIC TEXTILES FOR ARCHITECTURE
}

\section{Sarah Bonnemaison}

This account of a project for a 'warming hut' at the 201 I Canada Games in Halifax reveals how making use of the experimental framework provided by the pavilion type can allow architects to test the possibilities of a more responsive or interactive kind of environment.

Keywords: pavilion, architecture, electronic textiles, biofeedback, experiment, interactivity.

Sarah Bonnemaison was born and raised in Paris, but now works in Nova Scotia, where she takes inspiration from the sense of history in the Canadian province, its unique indigenous traditions, and its vital craft traditions and their adaptions in the face of changing technologies. She regards craft not as a traditional or hidebound practice but an opportunity to create new tools or explore better methods of construction. She teaches architecture at Dalhousie University in Halifax and reflects on the meaning of architecture through lectures, writing and the curating of exhibitions.

\section{Electronic Textiles For Architecture}

(Sarah Bonnemaison, Dalhousie University)

DOI: http://dx.doi.org/I0.5456/issn.2050-3679/20I3w/5sb

To view the images used in this article in a larger and more detailed format, follow this link: http://openartsjournal.org/issue-2/issue-2-galleries/article-I4 


\section{ELECTRONIC TEXTILES FOR ARCHITECTURE}

\section{Sarah Bonnemaison}

\section{Abstract}

This account of a project for a 'warming hut' at the $201 \mathrm{I}$ Canada Games in Halifax reveals how making use of the experimental framework provided by the pavilion type can allow architects to test the possibilities of a more responsive or interactive kind of environment.

\section{Introduction}

Some years ago, I joined forces with the weaver Robin Muller to design and develop electronic textiles for architecture. With funding from the Atlantic Innovation Fund, we formed the Architextiles Lab, called the @Lab for short. Our goal as principal investigators of a multidisciplinary team was to design and create architectural prototypes that integrate electronic textiles. Most research in the field of electronic textiles is for wearable items, like shape-changing and heatreactive clothing or wearable 'soft' computers. The military is a big client for this technology, using, for example, communication technology worn next to the body of the soldier. Our designs for electronic textiles focus on the built environment rather than the body.
They range in scale from a curtain to a pavilion. They also all explore various combinations of manual and digital craft, from slow tech to high tech. This short essay is an opportunity to present one project, showing the design process and completed prototypes, and also to reflect on our design-research process.

In general, the @Lab's prototypes integrate moving parts. They are as simple as a curtain sliding on a rod, and as complex as a collapsible pavilion that must telescope, pivot and fold to shrink to a small fraction of its volume. We learned about collapsible structures from camping tents, folding furniture and retractable objects. Textiles of course, have been valued for millenia for their lightness and portability. To add electronics to these deployable structures, we had to isolate fabric from structure, 'skin' from 'bones', in order to avoid damaging wires as the structure unfolded.

One of the most challenging aspects of working at the @Lab was the collaborative process. Like a film crew, we were a multidisciplinary team. But we didn't know what to expect as this was new for all of us. We had to invent a way of working together and continually adapt it throughout our years of collaboration: from the way we communicated with each other, to unexpected collisions when one discipline (or one material) met another. Over time, our weekly meetings became the core of our design process, a space in which we could clarify our intentions and examine our decisions from

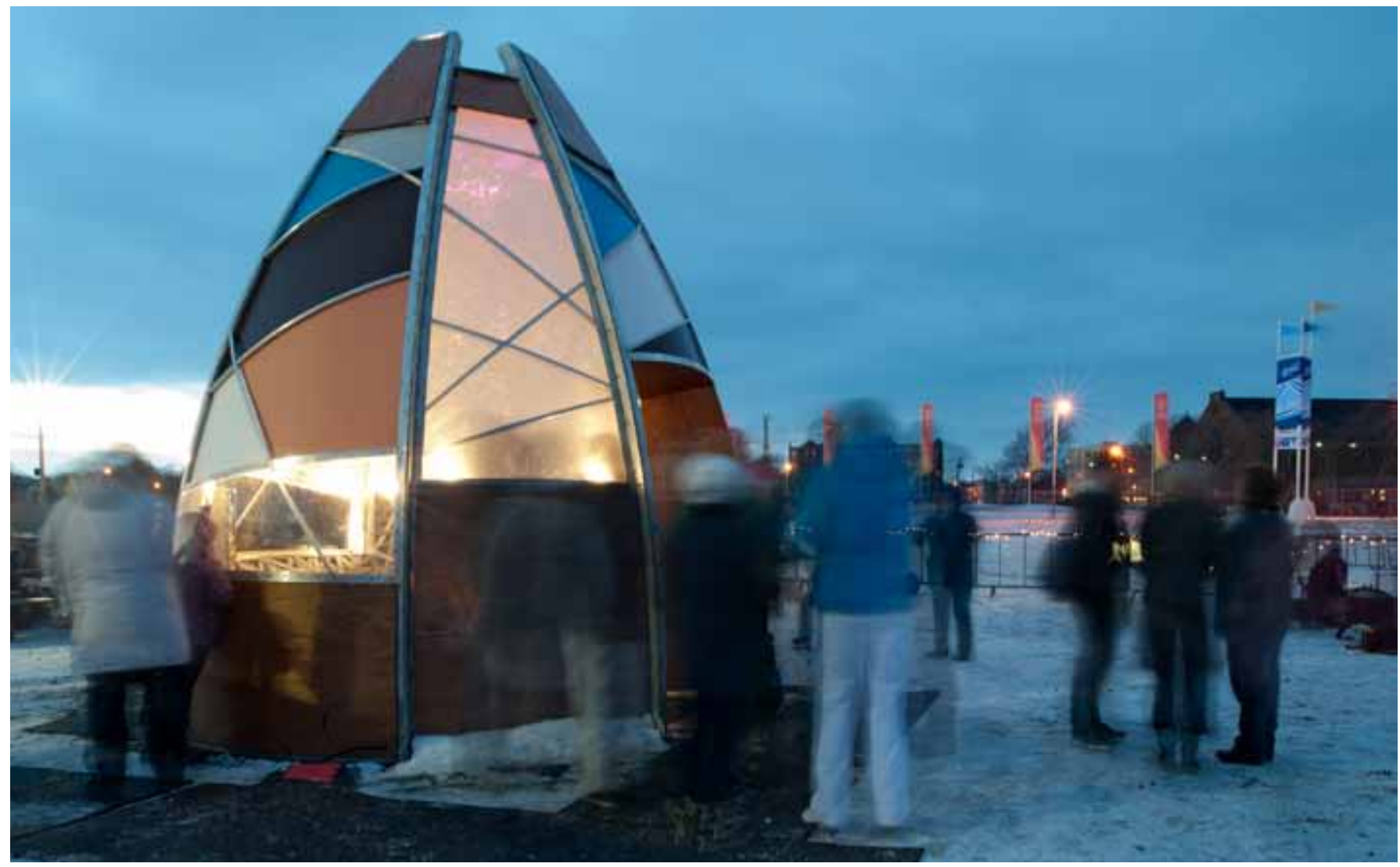

Figure I4.I: @Lab (Sarah Bonnemaison and Robin Muller),Winter Warming Hut, Halifax, 20 I I.

Courtesy of Sarah Bonnemaison. 
each discipline's point of view. We solved innumerable problems by 'mocking up', or building full-scale, portions of the prototype. This way, we could see where and how structure, fabric and electronics overlap, often in motion. Working in an open lab, we were able to design and build in an iterative process - planning, mockingup, detailing, and fabricating - with countless feedback loops at each stage, until we got the results we were aiming for.When you walk into @Lab, it feels more like an artist's studio than a laboratory - laser-cut fabric samples flutter from the walls, pinned next to inspirational photographs, records of past projects, and fragments of prototypes. Boxes of printed plastic joints squeeze hand-crafted models off the shelves, bolts of custom-made fabrics are stuffed between crates of electronics and spools of conductive thread.
We have learned that interdisciplinary design research is only as good as the members of the team. In fact, building a team with the right people may be the most critical determinant of success. We now know how to work together and can do so efficiently, effectively and with a great sense of personal and collective accomplishment. As my funding from the Atlantic Innovation Fund drew to a close, I began a new phase of work with the support of the Social Sciences and Humanities Research Council of Canada and more 'responsive environments' are now in process.

\section{Canada Games / Winter Warming Hut}

In the frozen and windy Canadian winter, when people look for social spaces, they are drawn to the small, the warm and the intimate. @Lab's next project was

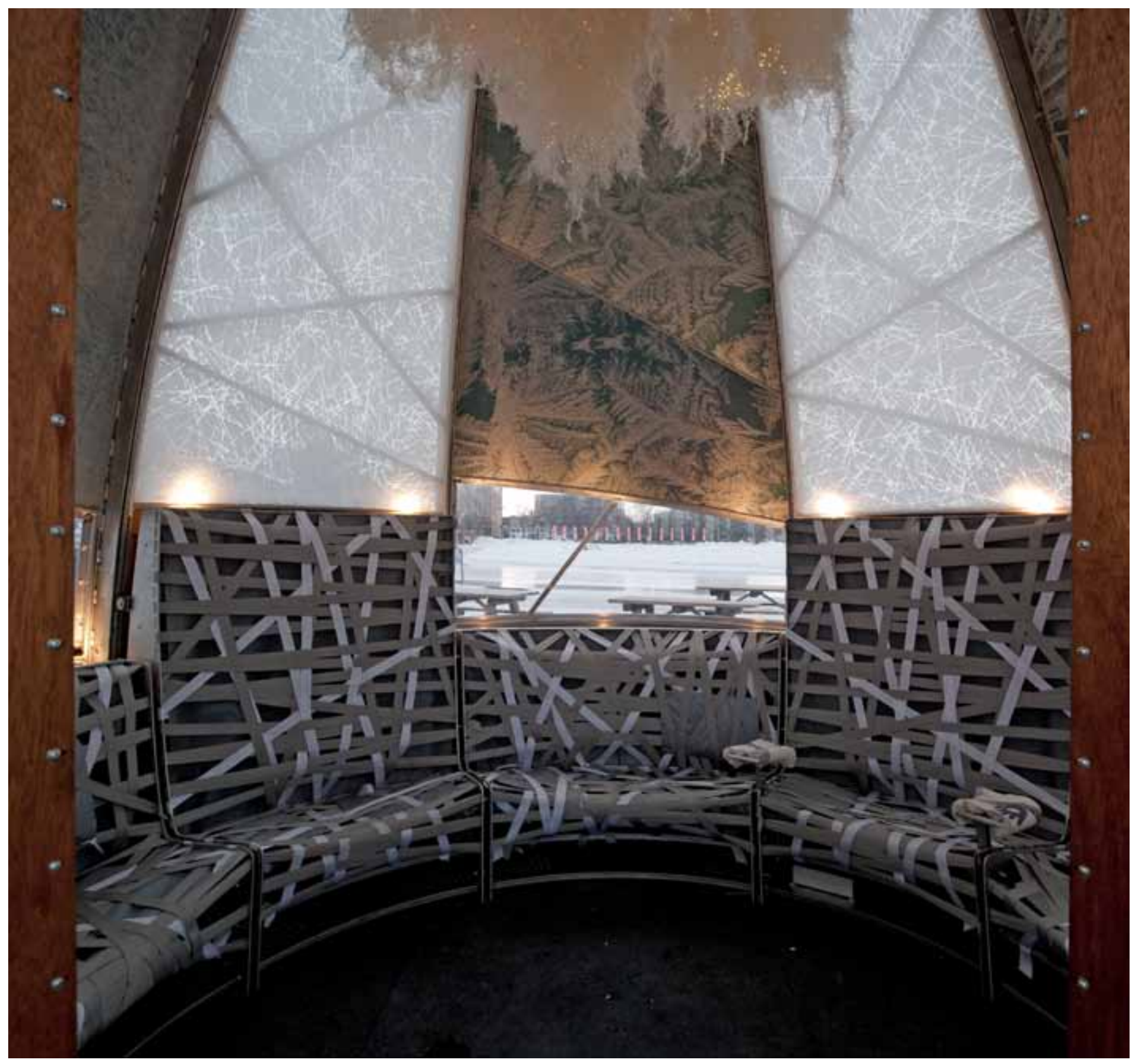

Figure 14.2: @Lab (Sarah Bonnemaison and Robin Muller), Interior view of the Winter Warming Hut, Halifax, 201 I. Courtesy of Sarah Bonnemaison. 
designed as that kind of space. The brief was a warming hut adjacent to a temporary 400-metre skating oval built on the Commons for the 20II Canada Games in Halifax. We conceived of this pavilion as a hard shell on the outside - protecting people from wind and snow and a warm and welcoming place on the inside, made of a seating circle, soft textiles forming a snowflake chandelier, and window through which people could watch the action outside. It would be like a jewel box encasing a social heart. The Commons is a large and windswept site, and any shelter built there must be high to be visible. The conical form of our hut was inspired by the heights of the tepees erected the previous summer, celebrating the 400th anniversary of the baptism of the great Mi'kmaq Grand Chief Membertou.

\section{Textiles}

In keeping with the jewel box concept, the hut's interior surfaces were covered with sumptuous handcrafted textiles. Custom-made Jacquards and burn out laces were unified by our wintery colour palette and decorative motifs such as criss-crossing tracks of skate blades on ice, frost flowers, and cascades of snowflakes. The motifs extended into the circular bench, its seats and the backs crisscrossed with grey and white webbing. The exterior of the hut needed to be wind- and water-proof.Working with our commercial partner Maritime Canvas Converters, we used a perimeter system they were familiar with, to secure panels of lexan, plywood, and a puncture-resistant architectural fabric to the structure. Our colour palette for the exterior was based on the muted colours of a Georges Braque still life - brown, light blue, white, pink and black - both visible and harmonious with the hut's grey and white winter setting.

\section{Architecture}

The most important design parameter for the hut's architectural structure was that it had to be durable enough to withstand the elements for three months at a stretch and yet be easily demountable, so city parks staff could erect it, take it down, and store it each year.While Cricket was designed for lightness and portability, the Warming Hut needed to be able to withstand the icy winds that howl across the Halifax Commons in February. This reinforced our decision to make a circular structure, streamlined on all sides to shed the wind. Ten feet in diameter at the ground, it narrows to three feet at the top. The aluminum frame is divided into eight boat-shaped sections, with marine ply sheer panels at their base and Lexan windows on every other section. Some of these windows were placed so

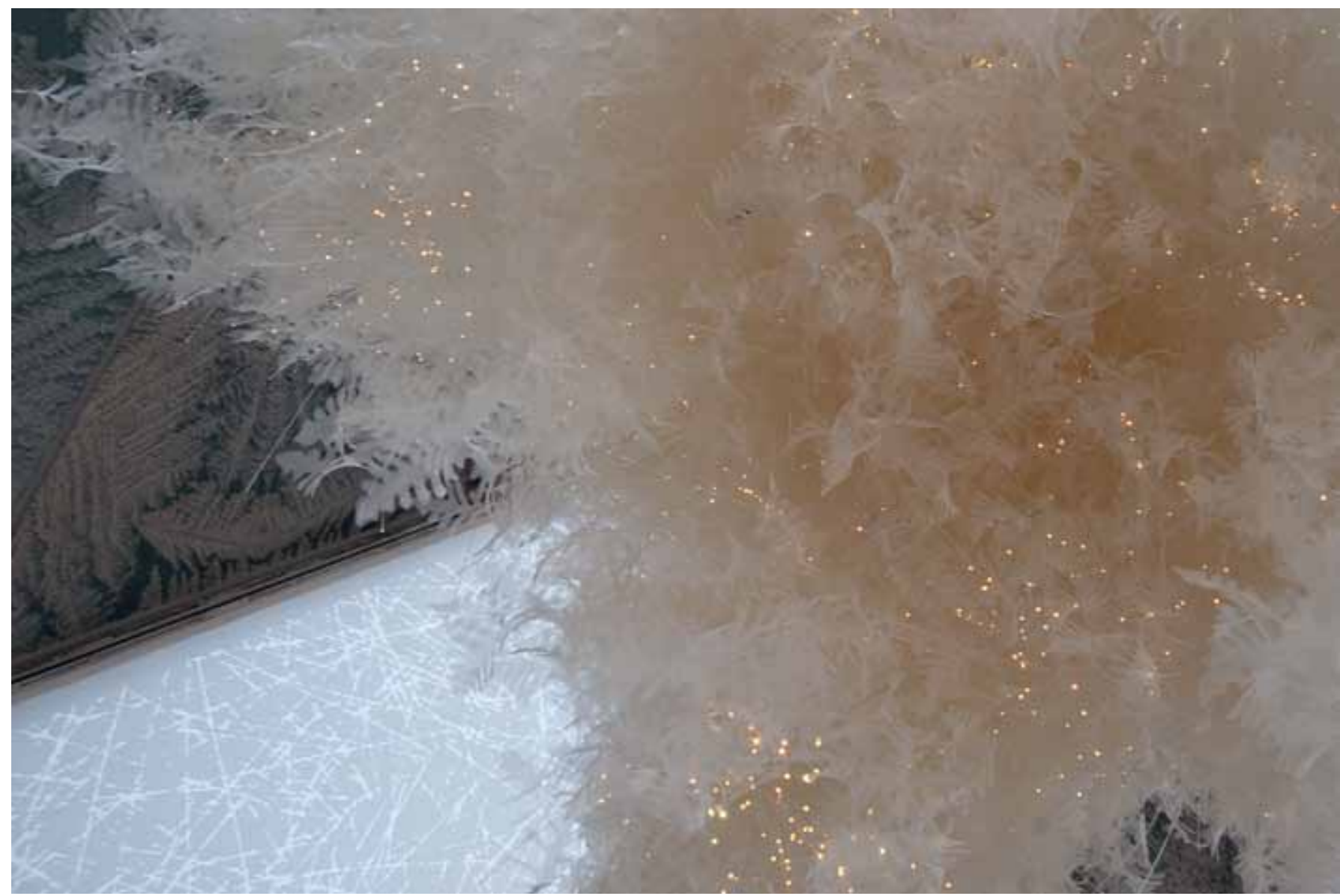

Figure 14.3: @Lab (Sarah Bonnemaison and Robin Muller), Detail of Snowflake Chandelier in the Winter Warming Hut, Halifax, 20I I. Courtesy of Sarah Bonnemaison. 
people could look out, while others were covered with decorative fabric to admit a filtered light. The sections were connected with bolts and anchored to the ground with tensile anchors installed before the ground froze. Erection took two days. In future versions, the bolt holes will be relocated to allow assembly of the sections from the inside, cutting erection time in half.

\section{Electronics}

The responsive features of the hut involved heating and biofeedback. We agreed at the outset to warm people on the bench, rather than trying to heat the air in the shelter.We combed the market for seat warmers - trucks, tractors, cars, medical applications - each with its own electrical requirments and performance features. A timer controlled the pads integrated into the webbed seating and spotlights concealed in the seatbacks lit up the shelter's interior surfaces.

Our research collaborator Alan Macy, an electrical engineer specializing in biomedical electronics, lent us his heartbeat amplifier (HBA) for the centre of our social warming hut. He designed this device which recognises a heartbeat and amplifies the electrical current associated with it in two dimensions amplitude and frequency. We used the frequency to create a sound effect of a very low frequency, or haptic, bass. The amplitude changed the color of fiberoptic threads in the chandelier, reflected by hundreds of organza snowflakes cascading from the top of the space. The pulsating chandelier and deep vibrations of the bass made the most intimate workings of a person's body public. People seemed to delight in this, mesmerised and fascinated by the commonality of the heartbeat we all share. People lined up to get inside the hut and have this experience, with friends and strangers looking on.

\section{The research challenge}

To experience the heartbeat amplifier, a person places their palms on two surfaces positioned to each side of the seat. Contact between the hand and the copper plate allows the body's own electrical current to flow from one plate to the other. In our Canadian setting, we had to worry about skin sticking to cold metal, so we electrically warmed the pads and made wool covers over each, asking people to remove their gloves. Once

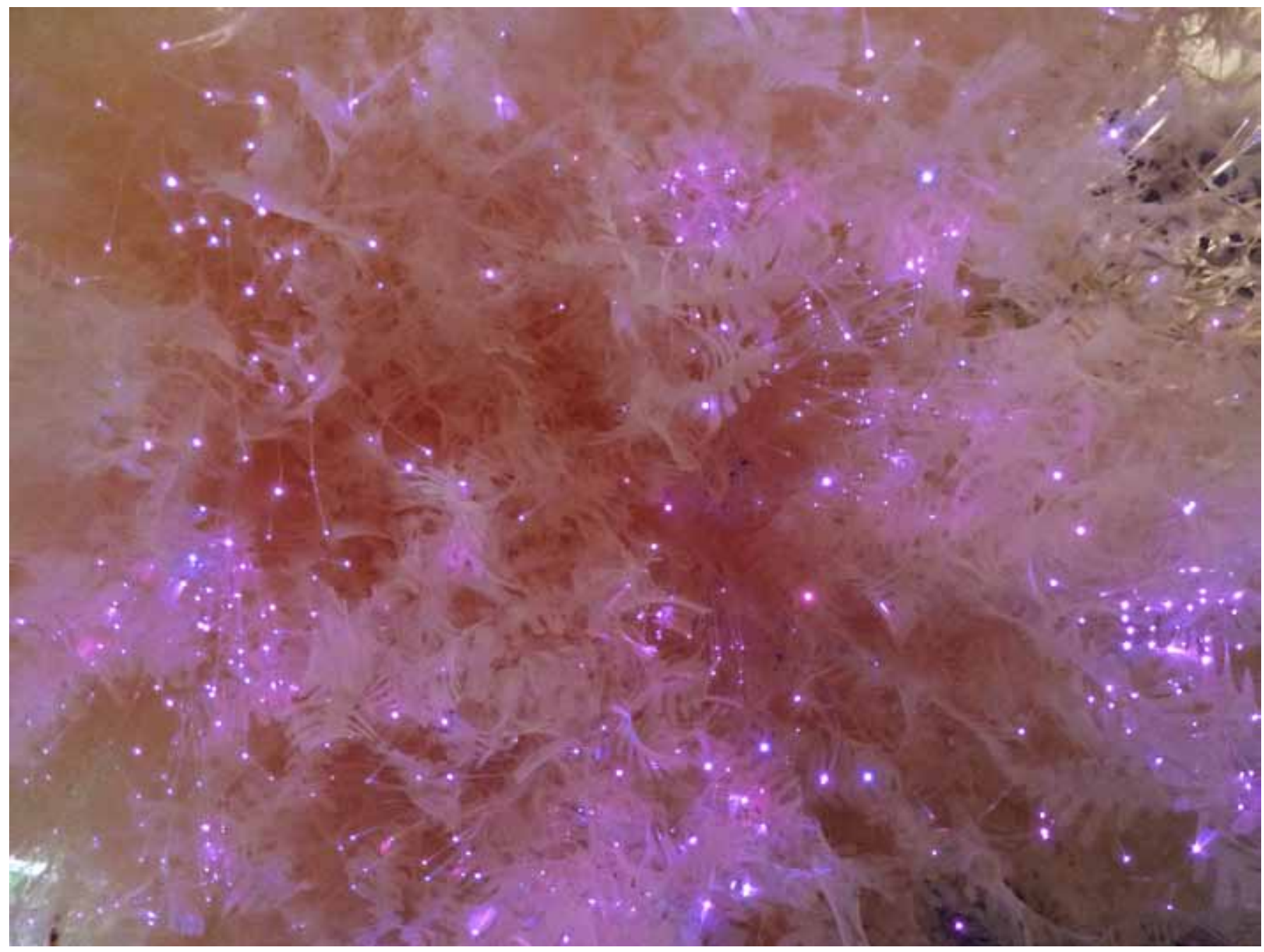

Figure 14.4: @Lab (Sarah Bonnemaison and Robin Muller), Detail of Snowflake Chandelier in the Winter Warming Hut, Halifax, 20I I. Courtesy of Sarah Bonnemaison. 
the hands are on the plates, the computer takes ten seconds to recognise the unique heartbeat of each person. If they fidgit or tense up, it takes longer - so we tried to make the seat comfortable and relaxing. The visually rich interior - with its unique textiles and wild chandelier - kept people still as they looked around, until the low rumble of the HBA began.
At the @Lab, we were fortunate to have the time and space to take on a creative project at this scale and be financially supported to sustain our research over four years. Looking back, the @Lab stands as an experiment in research and creation that proposes a way to work in today's design culture which, more than ever, draws from both art and science. 